\title{
Abstract
}

Despite the availability of new antiretroviral drugs and the simplification of treatment options, side effects continue to affect people living with HIV. In this paper, we present the findings of a grounded theory study designed to gain a critical understanding of the experience of side effects. Three main categories emerged from the data: the side effects, the experience, and the connections. The first category suggests that we need to change how we think about side effects in order to take into account the context in which they are experienced as well as the types and nature of side effects. The second category puts forward the idea that the experience of side effects is composed of three interrelated processes: becoming with, living with, and dealing with. Finally, the third category points to new connections that are formed with people, things and systems in the presence of side effects.

Mots clés adverse effects, antiretroviral, ART, grounded theory, HIV, side effects, toxicity

\section{"So far it's been choosing which side effects I want or I can deal with": A grounded theory of HIV treatment side effects among people living with HIV}

\section{MARILOU GAGNON \& DAVE HOLMES}

\section{Introduction}

Despite the availability of new (and supposedly less toxic) antiretroviral drugs in industrialized countries and the simplification of treatment options (i.e., all-in-one combination tablets such as Atripla $\left.{ }^{\circledR}\right)$, side effects continue to affect people living with HIV (PLWH). $[1,2,3,4]$ Short term and long term side effects are well documented in PLWH, although at present, it remains difficult to determine exactly how many people experience side effects and what side effects are most commonly reported.[2] Short term side effects typically include gastrointestinal toxicities (e.g., diarrhea, nausea, vomiting, and bloating), central nervous system toxicities (e.g., vivid dreams, off-balance or unsteady walking, light-headedness, drowsiness, feeling "hungover", feeling like falling over, spinning or room spinning, difficulty concentrating), fatigue, anemia, hypersensitivity reactions, and drug-induced organ toxicities.[2] Short term side effects can dissipate on their own after weeks and months of treatment, but they can also persist over time and have long-lasting effects on PLWH. Long term side effects include cardiovascular, hepatic, renal, metabolic, neurologic, and musculoskeletal events such as myocardial infarction, hepatotoxicity, renal dysfunction, dyslipidemia, insulin resistance, diabetes, lipodystrophy, distal sensory peripheral neuropathy, cognitive deficits, and bone loss.[2] In addition to the common side effects listed above, each antiretroviral drug currently available has a unique side effect profile and a comprehensive list of potential drug-drug interactions. [4]

The experience of developing and not being able to manage 
side effects is one of the most frequent reasons for treatment discontinuation or switch.[5] In fact, it is estimated that up to $25 \%$ of PLWH will stop their treatment within the first 8 months because of side effects, poor treatment adherence and / or treatment failure (i.e., inability to suppress HIV viral replication to below the current limit of detection, 40 copies/mL).[6] Side effects are known to contribute to poor adherence by making it harder to take antiretroviral drugs.[7] For PLWH, poor adherence can have serious consequences by compromising HIV-related outcomes (e.g., viral load suppression, CD4 cell count, progression to AIDS, and survival) and increasing the likelihood of developing a resistance to antiretroviral drugs which, in turn, can lead to treatment failure.[7] Side effects are also known to impact quality of life. In a cohort of 2066 participants, of which approximately two-thirds (66\%) had side effects, researchers found that side effects were associated with a substantial decrement in quality of life - comparable to the decrement of homelessness.[8] For the majority of PLWH, taking antiretroviral drugs is "a trade-off between poorer quality of life and being alive".[9 p252] At times, this trade-off is not sufficient for PLWH to keep taking these drugs and make sure they take them as prescribed. In this sense, side effects and their impact on quality of life can act as a powerful barrier to treatment adherence and treatment continuation.

To date, there has been very limited qualitative research on the experience of side effects from the perspectives of PLWH. Explorative and descriptive studies published to date are almost exclusively focused on treatment adherence (for an example, see [10]). Studies conducted on treatment adherence typically do not explore the experience of side effects per se but rather how that experience shapes the decisions and perceptions of patients who choose to switch or discontinue their prescribed treatment.[11] Although these studies highlight that treatment adherence or nonadherence occur in a particular context and in the face of particular conditions[10], they do not provide insight into the experience of side effects. This is also true of studies conducted on quality of life, most of which refer to the experience of side effects as a way to challenge the assumption that antiretroviral treatment (as a whole) is now simpler, more manageable, better tolerated, less toxic, and more effective. As Wong and Ussher[12] point out, this assumption is part of "a grand narrative about the lived experiences of PLWH that has the potential to marginalize the subjective experiences of those for whom HIV, and its related monitoring practices and treatments, continue to be sources of concern and causes of distress".[12 p128] As such, it fails to take into account that living with the treatment is "not just about living longer", [12 p117] but also about living healthier and at a higher quality of life.

Side effects are central to the experience of living with the treatment but rarely have they been studied alone (for example, see references 13,14,15,16]). Unlike other aspects of that experience, like quality of life[12], treatment adherence[17], health[18], and the imperative of achieving "good results" $[12,18,19,20]$, side effects have not benefited from the same level of empirical and theoretical engagement from scholars. In this paper, we present the findings of a grounded theory study on the experience of side effects. This two-year study was designed to: 1) gain a critical understanding of the experience of side effects, 2) explore an alternative approach that takes account of the multiple connections between the body and antiretroviral drugs, and 3) describe to what extent these connections constitute an important aspect of daily experiences and allow for more connections to be formed (with medicine, public health, nursing, community-based organizations, pharmaceutical companies, and so forth). For the purpose of this paper, we will primarily focus on the first objective of the study. The second and third objectives of the study will be discussed in a subsequent publication. Following a brief overview of the methodological considerations and sample, we will present a detailed overview of the study findings. Lastly, we will discuss the implications of the findings and some key recommendations.

\section{Methodological Considerations}

\section{Design}

This study followed the methodological principles of grounded theory as defined by Charmaz. [21,22] We opted for the work of Charmaz[21,22] because it is consistent with the constructivist paradigm as opposed to other methodological traditions within grounded theory. Constructivist grounded theory starts with the assumption that social reality is multiple, processual, and constructed.[22] This particular tradition of grounded theory stresses that social reality arises within a particular situation.[22] In order to gain a deeper understanding of the research phenomenon, researchers need to look at the total situation; that is, to look at the broader context in which the phenomenon is taking place and how that impacts the way people view their experiences, how they name things, what they know, how they know, and the actions they take.[22] Constructivist grounded theory offers a set of flexible yet rigorous methods that focus on the 
importance of gathering rich data and analyzing the stories of participants through an analytic process "that emphasizes understanding rather than explanation". [21 p126] In fact, the goal of constructivist grounded theory is not to produce an empirical generalization of the studied phenomenon in the form of a theory.[22] Instead, the goal is to conceptualize the studied phenomenon in ways that reflect the interpretive (and subjective) nature of the analysis and provide theoretical openings.[22] As such, the end product of theorizing can range from a complex substantive theory to the development of new categories or concepts. [22]

\section{Location and Recuitment}

This study was undertaken in Canada's capital region. This region includes the city of Ottawa (Ontario), the city of Gatineau (Quebec), and their surrounding urban and rural communities. Together, the province of Ontario and Quebec account for $65.9 \%$ of PLWH in Canada[23] After obtaining ethics approval from the Research Ethics Board at the University of Ottawa, we distributed using posters and recruitment cards in community-based organizations and specialized clinics in Ottawa and Gatineau. In order to be included in the study, participants had to self-identify as persons living with HIV and be able to communicate in French or English. All participants had to be 18 years old or older. Participants were be eligible to take part in the study if they were taking antiretroviral drugs or confirmed that they had been taking antiretroviral drugs less than 6 months ago. The goal was to include participants who could speak to their experience of side effects while being on treatment or after recently discontinuing their treatment. We believed that people who had not been on treatment for a longer period of time would not be able to fully recall their experience of side effects nor provide a rich description of that experience. For the purpose of this study, we did not undertake theoretical sampling. As highlighted by Birks and Mills[24], this form of sampling is not always possible due to the availability of participants and other access and logistic issues.

\section{Sample}

A purposive sampling strategy was used to recruit 50 participants. Data saturation was achieved after 35 interviews. We conducted 15 additional interviews to ensure that saturation had been completely achieved.

\section{Data Collection}

After completing the informed consent process, each participant was asked to fill out a short questionnaire, which included socio-demographic data, basic clinical information and a checklist of side effects. A summary of the sociodemographic and clinical information is presented in Table 1. A brief overview of the side effects reported by participants will be presented in the next section. Each participant took part in a face-to-face, semi-structured, in-depth interview with a member of the research team. The bulk of the interviews were conducted by the lead researchers and 3 research assistants. In average, interviews lasted between 4590 minutes. At the beginning of the interview, participants were asked to describe their experience with antiretroviral drugs over time and how they impacted their life in general and on a day-to-day basis. Then, they were asked to describe their experience with side effects with a particular focus on the way side effects manifested themselves, how they made them feel, what they meant, and how they were managed. Finally, they were asked to describe what it means to live with side effects. Each interview was audio-recorded using a digital voice recorder, transcribed, and reviewed by the led researcher. Field notes were taken after each interview. At the end of the data collection process, a research team meeting was held to discuss general impressions and recurrent themes in the interviews. This meeting was audio-recorded, transcribed and summarized by a research assistant.

\section{Data Analysis}

Data analysis began with the initial line-by-line coding of key interviews. The objective of initial coding is to summarize small sections of the transcribed interviews by assigning a code to each line. At this point in the analysis, explains Charmaz[21], the research team needs to remain close to the data and open to other analytic possibilities. After establishing some strong analytic directions through initial line-by-line coding, we moved to categorization. Categorization essentially seeks to elevate the analysis on a more conceptual level.[21] During this phase, each category and sub-category is constructed based on common patterns across multiple codes and common threads that describe what is happening in the data.[21] Working with the emerging categories, we used a technique described by Paillé [25]: take un-marked transcriptions and write the categories in the margins as opposed to the codes identified in the earlier phase of the analysis. This technique not only helped to solidify emerging categories but it also ensured that meaningful content was not left out during the categorization process. Finally, we moved to the last step of analysis by linking categories together - to move from a static position to a dynamic one.[21] This process allowed us to develop a visual representation of the experience of side effects (see 
Table 1: Socio-demographic and clinical profile of participants

\begin{tabular}{|c|c|c|}
\hline \multirow[t]{4}{*}{ Year of Birth } & $<1960$ & 9 \\
\hline & 1960-69 & 33 \\
\hline & $1970-79$ & 7 \\
\hline & No Answer & 1 \\
\hline \multirow[t]{3}{*}{ Gender } & Male & 37 \\
\hline & Female & 12 \\
\hline & Other & 1 \\
\hline \multirow[t]{4}{*}{ Ethnicity } & Caucasian & 38 \\
\hline & African / Caribbean & 6 \\
\hline & Latino / Hispanic & 1 \\
\hline & First Nations & 5 \\
\hline \multirow[t]{5}{*}{ Education } & None & 11 \\
\hline & High School & 14 \\
\hline & College & 14 \\
\hline & Undergraduate & 6 \\
\hline & Graduate Degree & 5 \\
\hline \multirow[t]{7}{*}{ Annual Income } & $<\$ 10,000$ & 9 \\
\hline & $\$ 10,000-\$ 19,000$ & 24 \\
\hline & $\$ 19,000-\$ 29,000$ & 10 \\
\hline & $\$ 30,000 \mathrm{~m}-\$ 39,000$ & 2 \\
\hline & $\$ 40,000-\$ 49,000$ & 2 \\
\hline & $\$ 70,000-\$ 79,000$ & 1 \\
\hline & $\$ 80,000-\$ 89,000$ & 2 \\
\hline \multirow[t]{7}{*}{ Year of HIV Diagnosis } & 1980-84 & 2 \\
\hline & 1985-89 & 7 \\
\hline & 1990-94 & 14 \\
\hline & 1995-99 & 9 \\
\hline & 2000-04 & 9 \\
\hline & 2005-09 & 4 \\
\hline & 2010-14 & 5 \\
\hline \multirow[t]{6}{*}{ Year of $1 \mathrm{st}$ Treatment for HIV } & $<1990$ & 2 \\
\hline & 1990-94 & 12 \\
\hline & 1995-99 & 14 \\
\hline & 2000-04 & 10 \\
\hline & 2005-09 & 6 \\
\hline & 2010-14 & 6 \\
\hline
\end{tabular}

Figure 1) and identify theoretical openings in our findings. For the purpose of this paper, we will focus exclusively on the empirical findings. The theoretical openings identified during the analysis will be discussed more explicitly in a subsequent publication.

\section{Results}

On average, participants were born between 1960 and 1969 $(66 \%)$. Most of the participants were male $(74 \%)$. Female participants accounted for $24 \%$ of the sample. The vast 
Figure 1: Summary of Study Findings

\section{The Side Effects}

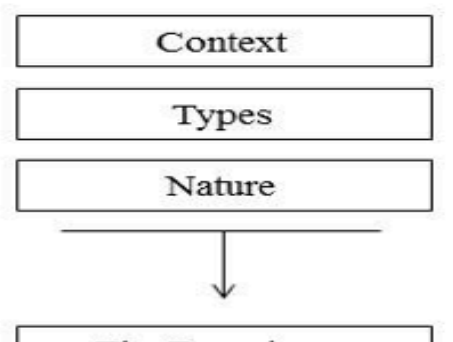

The Experience

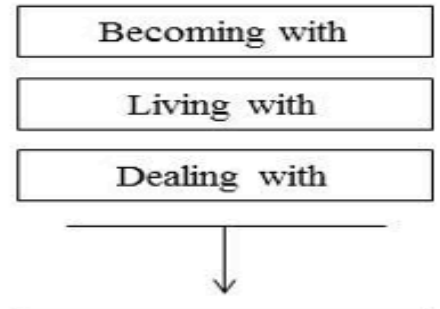

The Connections

\begin{tabular}{|c|}
\hline People \\
\hline Things \\
\hline Systems \\
\hline
\end{tabular}

were exposed to different first-line regimens depending on the time of initiation: 1996-1999 (14), 2000-2004 (10), 2005-2009 (6), and 2010-2014 (6).

Gathering information on side effects and summarizing it in tables proved to be challenging because PLWH experience a lot of side effects and are exposed to numerous treatment combinations over time. Table 2 summarizes the side effects reported by participants per body system.

During the analysis, three main categories emerged from the data: 1) the side effects, 2) the experience, and 3) the connections (see Figure 1). The first category suggests that we need to change how we think about side effects in order to take into account the context in which they are experienced, the different types of side effects, and the nature of the side effect experience. The second category puts forward the idea that the experience of side effects is composed of

Figure 2: Side effects (by body system) reported by participants

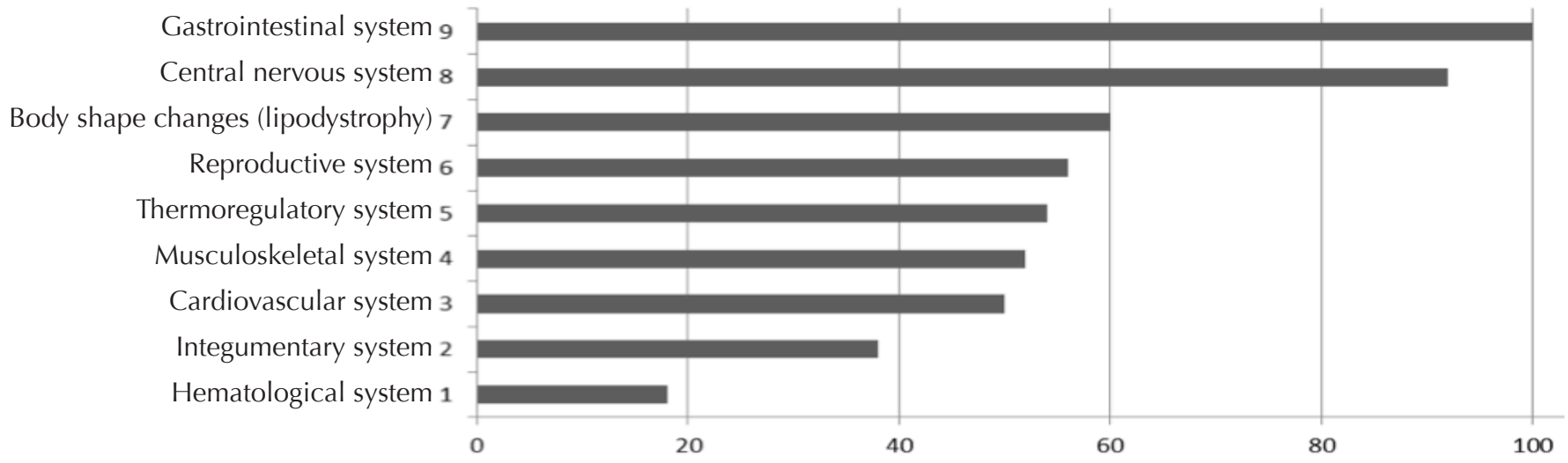


three interrelated processes: becoming with, living with, and dealing with. Finally, the third category points to new connections that are formed with people, things and systems in the presence of side effects. Each category will be presented in the following sections.

\section{Category 1: The Side Effects}

The context (defined here as the historical and treatment contexts) in which participants first experienced and continued to experience side effects as well as the types and nature of side effects were identified as key sub-categories during the analysis. Each one will be briefly presented in the next sections.

\section{Context}

Our analysis revealed that historical context is particularly important for understanding the experience of side effects because it gives us a sense of what was happening in the field of HIV when participants first started taking antiretroviral drugs. In the early history of the HIV epidemic (1980-1995), when HIV was considered a "death sentence", antiretroviral drugs took on a particular meaning for PLWH as suggested by the following quote.

So overall, I'm happy that I got these medications because they allowed me to still be alive, I think, today, because when I was given the diagnosis in 1991 ... I was given 2 years [to live]. In 1993, I was gone ... But thanks to the medications, I was able to have a normal life. So I tell myself: "O.K., there have been some unfortunate side effects, but relatively well tolerated, and it allowed me to still be here today." (Informant 1, lines 26-34)

Historical context not only gave a particular meaning to antiretroviral drugs, as life-saving drugs, but also to the experience of side effects. The above quote clearly illustrates that when we take into consideration what was happening at that particular point in time, we can understand how side effects were and continue to be seen as "a price to pay for being alive".

In the 1980s and early 1990s, taking antiretroviral drugs was indeed a matter of life and death. It is true that PLWH were dying of AIDS in large numbers. But it is also true that many PLWH were dying because of the antiretroviral drugs.

Okay. Um, I think it was early '90's, 1990 to 1992, I... they gave me AZT by itself. Um, as soon as I started to feel yucky on it, I was not taking it consistently. And then I heard through the community that everybody was dying from it. So I said, pfft! I said, "Stop it". Then, the doctor came out with DDI, these big horse chalky pills. And for some reason, that didn't work either. Uh, it worked probably, but I just thought it was poison, I was... at that point, I was scared off of it, you know, I didn't trust it. And so then that was it. I didn't take any HIV medications until 1997. (Informant 2, lines 8-15)

Taking antiretroviral drugs at a time when we knew very little about them made PLWH realize how serious and deadly side effects could be. Participants recalled hearing "horror stories" (as one participant put it) about the toxicity of AZT (Zidovudine or Retrovir ${ }^{\circledR}$ ). As a result, many of them opted to stay away from AZT and other drugs under investigation at the time. Some were even discouraged by their own physician from taking AZT. Others who were prescribed AZT stopped taking it. Needless to say that drug toxicity dominated the early history of antiretroviral drugs and shaped the way PLWH viewed these drugs - as both life threatening and lifesaving.

The majority of participants started taking antiretroviral drugs during the era of combination therapy between the late 1990s and early 2000s. This era was marked by a dramatic increase in the number of antiretroviral drugs available on the market and the number of combinations possible to treat HIV. Taking antiretroviral drugs and managing side effects became a "full-time job" for PLWH. The pill burden, strict medication schedule, and lifestyle modifications (food intake, fluid intake, activities of daily living, etc.) were repeatedly mentioned by participants who started taking antiretroviral drugs at that time. This is clearly captured in the following quote:

I've changed medications probably 10 times in 19 years (...). My challenges in the beginning was I had to take, I was taking like 24 pills a day on four different schedules. So I had to take one every six hours or some every six hours, some every eight hours, some with food, some without food. So, in the beginning, taking my medication was like a full-time job. Then, they started getting a little bit easier, uh, for taking. The side effects didn't get easier. (Informant 3, lines 10-18)

During the next two decades, antiretroviral drugs became "easier to take" but side effects remained very present in the lives of participants. This is largely due to the fact that PLWH rarely stay on the same treatment regimen for a prolonged period of time.

Over the course of their treatment, PLWH are exposed to many antiretroviral drugs. In fact, it was not uncommon for participants to struggle trying to remember previous treatment regimens because there were simply too many to remember. The next quote illustrates this:

Oh my God! Okay, that's a big one. Okay. Um, past medications, I mean, I've been on the... most of the 
medications since the start. (Informant 4, lines 10-11)

There were several reasons why participants had been on so many different treatment regimens. Common reasons for "switching" treatment regimen included the evolving state of knowledge on antiretroviral drugs and ways of treating HIV, changes in treatment guidelines, new treatment options, treatment failure, and viral resistance. Participants ranked side effects as by far the most important reason for "switching" treatment regimen. All of the participants had changed their treatment numerous times because of side effects. In fact, "switching" became one way to deal with side effects. We will get back to this idea in the second category.

Um, with past medication, it didn't work very well and I had, uh, I had side effects from it. Um, something from weight loss to, uh, not being able to sleep or waking up in sweat, you know. So, uh, the current medication I'm on right now is a lot better than what I was on and it's less medication. Like, when I started, I, I was on five or six pills and now I'm down to three. (Informant 5, lines 5-9)

Participants developed side effects in various treatment contexts: during pregnancy, during a clinical trial, after the initiation of their first treatment regimen, after switching to a new regimen and / or a newly marketed antiretroviral drug, after switching one antiretroviral drug in their regimen, after switching back to a previous antiretroviral drug, and so forth. Paying close attention to context proved essential to capture the diversity of experiences reported by participants ranging from severe hepatotoxicity during a clinical trial to disturbingly vivid dreams after switching back to a previous antiretroviral drug. We quickly found that side effects took on a particular meaning depending on the treatment context. This was clearly articulated by a female participant who had experienced severe drug toxicity during her pregnancy in 1997, stopped taking antiretroviral drugs altogether, and started again in 2012 on what was supposed to be a "low side effect regimen".

I didn't start taking medication when I was first diagnosed, because I, I just didn't want to. I didn't... that was in '94 and, um, medication side effects were pretty bad then. And I just didn't want to. So I didn't. And so I started taking them in 1997 when I got pregnant. And, in 1997, you took, if you weren't already on medication, you started taking AZT at the beginning of the second trimester and then you took AZT and 3TC through the third trimester. And at that time, it was really high doses. I was taking 1200 milligrams of AZT and I was dying. It killed me. It like killed me, killed me, killed me. So the day I had my baby, I stopped taking medication and I didn't take any medication until 2012 (...) But in 2012, I started taking medication again and I again had like a terrible... I, I don't know what it is about me and side effects but I seem to have a lot of side effects (...) I'm currently taking Isentress and, um, Truvada. It's not great. It's not great. I've promised the doctor I'll do... I think I'm at like three more weeks and see how it is and I'm considering going off. He'd like me to try something else, but I can't live with the side effects. So... and I know this Isentress and Truvada are supposed to be low in side effects and it isn't for me. (Informant 6, lines 3-19)

\section{Types}

Based on our analysis, we identified different types of side effects. Participants spoke of side effects that were immediate - progressive, transient - permanent, hidden - visible, and minor - severe. Instead of presenting each type separately, we will link them to each other in order to better reflect the experiences of participants and the complexity of side effects.

All of the participants interviewed had experienced immediate and progressive side effects to various degrees. Immediate side effects appeared right after starting a new antiretroviral drug or treatment regimen.

The first night [after starting the medication], I had a huge headache. The next day, diarrhea. And then, somnolence and ... Nausea ... Then hard stools, things like that (...) RA: When did you notice these side effects? Well, when I started the medication. RA: Immediately after? Oh yes, yes. The first day I took it, it started. (Informant 7, lines 13-31)

Immediate side effects typically included gastrointestinal toxicities (e.g., diarrhea, nausea, vomiting, bloating, etc.) and central nervous system toxicities (e.g., somnolence, headaches, feeling hungover, vivid dreams, etc.). But they also included potentially life-threatening side effects such as organ toxicity (e.g., hepatoxicity), cellular toxicity (e.g., lactic acidosis), and hypersensitivity reactions (e.g., rash, exanthema, Stevens-Johnson syndrome).

I was asked if I would volunteer [in a clinical trial] and I said, "Sure". (...) But it was something out of a weird freaking movie. I remember leaving class and feeling nauseous and I don't... I didn't even make it to the bathroom (...) And I remember, you know, I was, I was so violently ill (...) I went home and I called my doctor and he said, "Get, get down here right away". And, uh, that night, I was admitted into the hospital and I stayed there for a good week if not longer with liver damage. (Informant 8, lines 117-140)

Participants would often make comments to the effect that immediate side effects were easy to recognize as "real side effects" because they coincided with the beginning of a new antiretroviral drug or treatment regimen. Progressive side effects, on the other hand, were not so easy to recognize. They developed slowly and included more subtle changes in energy level, mental state, comfort level, functional level, 
and body shape. One participant perfectly captured the essence of progressive side effects when he described the following experience:

So I developed drug-induced hepatitis. I had no idea. It took probably four to six months for me to get sick enough and get tested and then for them to realize, "You have hepatitis", stopped the Delavirdine (...) I remember once a friend saying, "Do you want to go for a walk?" I looked at him, I said, "I've got to go back down and lie down". (...) I said, "I'm wiped, I'm tired, I can't do this". And it was only after that happened for a little while that I realized something's wrong, something's off. And it was drug-induced hepatitis. (Informant 9, lines 89-103)

Participants made a point of highlighting the difference between transient and permanent side effects. Transient side effects only lasted for a short period of time (days, weeks or months) and disappeared on their own. They were often seen as sign of the body adjusting to antiretroviral drugs. This participant explained:

Well, when I first started the cocktail in 2006 with the Kivexa and the Kaletra, um, of course, it was brutal, for the first 6 weeks to 12 weeks, first 3 months maybe, just for my body to get used to it, like, I had a lot of side effects like diarrhea and it was really hard on my stomach. Like I had to take away food and then, and then eat again, and then eat again just to kind of suppress the... And I was eating Tums like crazy. I had to sleep up right because I had to take some at night before bed so you know, it was an adjustment period. (Informant 10, lines 17-24)

The idea that some side effects were only temporary encouraged participants to continue taking antiretroviral drugs and push through the "adjustment period". This idea was also reinforced through interactions with health care providers during which side effects such as diarrhea, bloating, nausea, vomiting, somnolence, fatigue, and grogginess were commonly described as "part of the package".

Like, um, I get a bit of nausea, nothing too bad, a bit of gas, no vomiting or diarrhea so... That's good. I knew that side effects were gonna be, uh...part of the package. My doctor and my nurse, uh, I mean they were just reassuring me that those are... they're all part of the package as I just said. So... And, um, like I said they subside and, I don't know, you just learn to deal with it. (Informant 11, lines 23-40)

While it is true that some side effects are transient in nature, it is wrong to assume that this is the case for everyone. Many participants reported living with side effects that never completely disappeared on their own. Diarrhea was the most commonly cited example of a side effect that can be transient for some and permanent for others. Our analysis revealed that permanent side effects were very diverse ranging from chronic diarrhea to blurred vision, peripheral neuropathy, memory loss, body shape changes, fatigue, headaches, cognitive changes, diabetes, and pulmonary hypertension, just to name a few. As such, they not only included side effects that did not subside over time, such as chronic diarrhea, but also those permanently inscribed in the body (e.g. body shape changes).

Throughout the interviews, participants made important distinctions between hidden and visible side effects. Hidden side effects were considered to be preferable because they did not disrupt social interactions as much as visible side effects. For example, one participant (Informant 1) explained that living with drug-induced diabetes and cardiovascular disease was far easier for him than living with body shape changes (known a lipodystrophy). During the interview, he kept going back to the idea that visible side effects expose PLWH and puts them at greater risk for involuntary disclosure, stigma, discrimination, rejection, and social isolation. This was true for other participants who reported body shape changes but also for participants who lived with chronic diarrhea.

Uh, with my own family, my siblings, I don't feel comfortable with having side effects, uh, if I'm visiting them. I'm always afraid that, uh, they get fed up with me having the side effects. One sister doesn't, uh... if I wake up in the morning and say that my stomach is gurgling, then she'll say, "Well, we're not going to go anywhere" even though we had planned a trip. So it... I don't know if it's an embarrassment for her, if I have to go, say, you know, the next gas station, I got to go (...) I'm afraid to go to her house for fear I will have diarrhoea or if I coughed, I end up with diarrhoea and embarrass her, you know. So we don't go out to see them. (Informant 11, lines 292-309)

It also resonated with the experience of one participant who struggled with an atypical side effect that made his mouth extremely pasty and dry.

I'm scared to reach out to people and be rejected because I'm not pleasant. I've had no intimacy for two years. Nothing is happening on that front. I don't feel like ... In fact, really, I don't feel I can offer who I am right now to someone else. So I move further away from people and when I'm physically closer to people, I'm really careful with the way I breathe, not getting too close, no sexual intimacy. (Informant 12, lines 177-182)

Visible side effects had a greater impact on the way participants felt about themselves. Experiencing body changes and having less control over bodily functions made them feel diminished, embarrassed, sad, and vulnerable. This was very different from the experience of participants who only reported hidden side effects even if they had serious health consequences and a greater care burden. By 
remaining invisible to the self and others, these side effects automatically became more manageable.

The last category emerged out of the way participants talked about the impact of their side effects. Side effects were considered minor when they were manageable and did not impede on daily life activities, social interactions, selfesteem, and overall health.

Well, everything is manageable. So health wise, I mean, I have this layer of fat but it's... I still think I have a good cardio vascular system because I still have a jog every day. So this is not really... it's not like I have... my arteries are blocked and I'm overweight or something. So my health I feel is not bad. RA: It's not too bad even with all the side effects? Yes, everything is manageable and everything is... when the pains come, I have some analgesic or some other things that I can take so everything is manageable. (Informant 13, lines 210-216)

As suggested by the above quote, the ability to manage side effects through various strategies such as lifestyle changes, medications, and treatment switches shaped the way participants viewed and described their experience. For example, participants who were able to manage their druginduced diabetes, hypertension, myocardial infarction by taking medications considered these side effects to be minor. We documented the same pattern among participants who were able to manage gastro-intestinal toxicities by changing their diet and participants who found creative ways to lessen their side effects: adapting their schedule, changing position slowly, avoiding alcohol or caffeine, modifying their medication schedule.

You just learn to deal with it. You figure things out. Don't eat that if it'll upset your stomach. Um, take your pills at a different time of day, or try at, at night or anything. (Informant 14, lines 40-42)

Severe side effects were those that could not be managed or "dealt with" no matter what strategy was put into place. They were not considered severe from a clinical standpoint, but they were in the eyes of participants. For those who experienced dizzy spells, blurred vision, taste alteration, bloating, anorexia, unpredictable bouts of diarrhea, hair loss, body shape changes, peripheral neuropathy, headaches, vivid dreams, and insomnia, the impact was indeed very severe. This is because side effects altered their self-esteem and ability to function, enjoy food, eat, go out, socialize, walk, sleep, rest, and read. As one participant put it, severe is when "something that could easily be managed, turns into something where you want to throw yourself off the balcony" (Informant 15, lines 388-389)

\section{Nature}

Based on our analysis, we identified three inherent characteristics of side effects: 1) they are unpredictable, 2) they are unstable, and 3) they are highly individual. There is a certain degree of predictability when we think about the most common side effects. For example, we know that the vast majority of PLWH will experience some gastro-intestinal disturbances at some point during their treatment. But for the most part, it is impossible to predict how one will react to antiretroviral drugs. This was mentioned numerous times throughout the interviews. The most striking examples of unpredictability came from participants who had taken part in clinical trials, which are conducted in large numbers in the field of HIV.

I was on trial drugs at the time. And the people that put me on the trial, when I told them about the hair loss, they didn't believe me until one day I thought, "Okay, today, I'm going in. I'm going to wash my hair. I'm going to take all the hair that I do just from shampooing my hair and bring it to them. And I guess about six months later... oh no, a year later, um, I had to call the doctor about... it was when they were on call. And I said to the doctor, I said, "That's it. I live on the 12th floor and the pavement down below looks really good." So he told me to stop the medication. I became so depressed and they put me on a newer regimen. But still, the side effects were phenomenal. (Informant 11, lines 5-13)

Side effects were considered to be unpredictable because there is no way to tell which ones people will experience. It is impossible to know if, when and how they will manifest. As such, there is always a certain unknown and anxiety with every treatment regimen. One participant pointed out:

Maybe changing [treatment] isn't such a bad idea or it's an option at least ... However, what am I getting into? There's a whole new can of worms there... I'm opening up if I... it's like, it could be worse. It could be 10 times more... Do I really want to go down that? Is it really that bad that I can't, uh, continue taking? And the answer, the short answer is, "No, I'm going to continue taking it until, um, we'll see what's around the next bend." (Informant 16, lines 561-573)

For many participants, the number and the types of side effects came as a surprise. They did not expect what happened to them once they started taking antiretroviral drugs. This was clearly highlighted by the following participant:

I knew there were going to be side effects but I didn't know there was going to be so many on certain levels, you know? Like the dizziness and the, the spots and the hearing and the beeping in the ear and ... Everything is, is not me, it's, it's my medication telling me something is wrong, you know. (Informant 17, lines 54-58) 
It was generally recognized that most side effects are no static; they change from one day to another and evolve over a longer period of time (weeks and months). Because of this, they were considered to be somewhat unstable. Not knowing how they would feel from one day to the next put participants in a challenging situation, especially when it came to their family, work and volunteer obligations.

I didn't work for a lot of years. I was on [social assistance]. Like I'm still on [social assistance] but now I can, you know, work here and there and I do a lot of volunteer work as well. But, uh, so because I couldn't rely on my health ...Like one day I was feeling $100 \%$ and, and then a couple of days later, I'm like, "Oh, my God!" I can't leave the house because I, you know, I have diarrhoea or, or, uh... just stuff that, you know, regular 20 year-olds, 30 year-olds don't worry about, you know. I worried about it a lot. (Informant 10, lines 219-224)

Not being able to plan ahead was common to all participants.

I'm not able to work anymore. I do some volunteer work. But I can't say that I'm going to be there at a certain time at a certain day because I'm not, I'm never sure, uh, you know, uh, everything's always tentative, like, you know, as long as I feel all right, I'Il be able to go. But I can't say for sure that... I can't say that I'm going to absolutely be there on time. (Informant 18, lines 70-74)

This was true for daily activities and for hourly activities throughout the day. Planning activities from one hour to the next was a challenge for participants who experienced the most unstable side effects: diarrhea and vomiting. During the interviews, participants highlighted the fact that diarrhea and vomiting were prone to change quite frequently and rapidly - within minutes, hours, days, and months. As a result, they often led to embarrassing situations in public spaces or social gatherings.

And the Ritonavir in there changed the taste in my mouth and made me projectile vomit. I would eat, I'd walk out of the restaurant and I would throw up with five minutes. And I remember walking down the streets and all of a sudden cough (coughs) and then all of a sudden, everything I'd eaten had come out on the street. (Informant 9, lines 43-47)

When you're in the streets... I've driven in a car and said to somebody, "Pull over." And they're like, "What?" "Pull the fuck over now." Because I knew I was going to shit in my pants. (Informant 9, lines 271-274)

Similar situation were reported by a large number of participants, many of whom continued to struggle with chronic diarrhea after years of being on treatment.

Side effects were considered to be highly individual. Participants would often go back to the idea that side effects are different from one person to another.

Expect anything. You can expect anything and everything. It's not the same from one person to another. Don't listen to the others. The examples and opinions of others even if they take the same medication. It's like a pair of underwear ... They won't fit everyone the same way. (Informant 19, lines 10-16).

Some participants, like informant 19, believed that side effects were unique to each individual. Therefore, they did not see the value of consulting others PLWH as part of their own personal experience with side effects. This was not unanimous across our sample. Many participants acknowledged that everybody is different but saw the value of looking to others for advice and first-hand knowledge. This was the case for informant 20 who said the following:

I look it up and read what the side effects are and what people's experience has been, even though I know everybody's different and individual with these pills. (lines 134-136)

The individual nature of side effects was often mentioned when participants talked about importance of "knowing yourself" and findings "what works for you".

If, if you know that this will make you sick, but this will make it a little better, you're going to stick with what makes it a little better, even if in terms of it doesn't probably work as well or whatever as something else does, you found that that does and for each individual person, different things work at different levels. I can't tell you, "Oh, drink chamomile tea to make it all better" because that might totally not work for you. It's all your own personal thing. And you just kind of sort of got to keep track of what you do and what made you feel better, what was it that made you feel better, stick to that." (Informant 15, lines 442-452)

Finally, individuality was strongly emphasized when participants discussed the differences between the way men and women experience side effects. Women who took part in the study pointed out on numerous occasions that antiretroviral drugs fail to take into account the unique characteristics of the female body resulting in side effects that are more severe, more frequent, and different than what we are used to.

People that I talked to at that time who I could confide in, they would have similar side effect but not as strong. So then I realized that men side effects are different from the women side effect. And, uh, that was interesting. Like, how different the men's body is compared to the women's body and how different pill reacts to either one, you know. (Informant 11, lines 132-136) 


\section{Category 2: The Experience}

At the core of the experience of side effects, we found three interrelated processes: becoming with, living with, and dealing with. For the purpose of this paper, we will go through a detailed description of each process separately. However, it is important to point out that the three processes work together to shape the experience of side effects.

\section{Becoming with}

Throughout the interviews, we found that the experience of side effects was described as a process of becoming as opposed to a state of being. In other words, it was a process through which participants came to experience themselves as both healthy and sick. It was also a process through which participants became other versions of themselves and redefined their "normal". These three sub-categories will be further explored in the next sections.

The way participants talked about the experience of side effects really challenged the way it has been portrayed in the literature to date. Side effects were not just unpleasant consequences of antiretroviral drugs. They were fully engaged in a process of becoming whereby participants got to experience health in the context of HIV. In this context, health was defined as "being alive", "maintaining higher CD4 (or T cells) counts", and "having an undetectable viral load". While this narrow biomedical definition of health was challenged by most participants, it always found its way through the interview.

I find that they (medications) are keeping me alive longer, they're bringing... They're going on my CD4 counts and my viral load. My viral load is undetectable and my CD4 count when up higher. They're keeping me alive (...) Even with these side effects, yes, because it's keeping my viral load undetectable. That's the main thing, and your CD4 count's up high. (Informant 23, lines 3-5; 52-53)

Becoming healthy by achieving high CD4 (or T cells) counts and an undetectable viral load became a defining feature of the experience of side effects. In response to this, participants would often point out the irony of the process because of how much pills they were taking and how hard these pills were on their bodies.

Well, my health is getting better. I mean, that's, that's the ironic thing, despite the fact that I'm taking, you know, about 20 pills a day (Laughs), uh, and inhalers and stuff, my health seems to be getting better. My viral load's been undetectable for, you know, about 10 years now. My T cells are higher ... I remember at one point I was walking around, I had two T cells. So... and my viral load was really high. So you know. So, I mean, it's completely turned around and I feel better in a lot of ways, you know. (Informant 4, lines 110-117)

For all of the participants, side effects became part of what it feels like to be healthy as a person living with HIV. As such, they came to understand that health (as defined in the context HIV) came at a price and did not feel "right" most of the time. During the interview, many participants argued that becoming healthy "on paper" (expression used by Informants 22 and 23) (i.e., through CD4 and viral load measurements) made it more difficult for them to be heard and have their side effects properly assessed, recognized and managed in the clinical setting. This is because side effects were seen as a "normal" part of the process - something that you have to live with and accept as part of becoming a healthy person living with HIV.

In the process of becoming healthy (as defined above), participants also became sick. It was difficult for participants to make sense of this contradictory experience. On one hand, they were told by health care providers that they were healthy and managed to achieve a certain level of health on "paper". On the other hand, they felt sicker than ever before and had poor quality of life. This tension was highlighted by the following participant when she said:

Honest to God, I would rather live a... it's hard to say, but I would rather live less amount of times without medication than take the medication (...) I've got stuff happening that they say is related to HIV. I've got problems with my heart and problems with blood pressure and like just cardio stuff (...) I've never had any serious things from HIV. So now that I'm having more serious things from the medication, it's like, to me, it doesn't make a lot of sense (...) I'm worse than I was before I took it. Like I felt better before I took it. So why am I taking it? It's like it's just frustrating. (Informant 6, lines 56-73; lines 170-171)

The process of becoming sick through the experience of side effects was common to all participants. Not only did side effects make them feel sick, but it also turned them into "sick people" with particular obligations, needs, and limitations. The next quote supports this:

Living with the effect of medication ... It basically means that I'm sick. It means, well, here's the result of this virus that must be controlled. We have to control it to stay healthy and at the same time, it causes side effects. So for me, that's what it means. For me it's like, "yes, you're really sick" and "yes, your capacities are diminished" (...) Because of the medications, I have this, I have that. It never ends. (Informant 24, lines 291-312)

Side effects also acted as a constant reminder of being sick. Many participants mentioned during the interview that HIV 
did not make them feel sick or remind them of being sick. It is through the experience of side effects that HIV materialized and became real for them. One participant clearly explained it when he said that "the greatest side effect is psychological because he was reminded every day that he was infected" (Informant 9, lines 259-260). Overall, the process of becoming sick was very hard on participants. When we interviewed this participant, he struggled to contain his emotions when he said the following:

It's very disappointing to see how much it does affect your health. I mean I'm 48 right now and, you know, uh, I was in my thirty's when I got it and, uh, I, I used to be extremely active, extremely fit and very outgoing, very... lots of energy, uh... But taking the drugs took that all away from me. (Informant 25, lines 113-116)

A number of participants described how side effects had profoundly changed who they were and how they saw themselves as professionals, lovers, friends, relatives, parents, social beings, and members of society. Through side effects, they became lesser versions of themselves with less capacity to work, love, engage, provide, and take part in society. One participant captured the process of becoming a lesser version of yourself when she concluded the interview by saying:

It's like I'm not as good a me as I could be without these side effects. And it's like I really struggle with the fact that, you know, the side effects lower the quality of my life, but I'Il live longer, which I don't know that I'd rather live longer with a lower quality of life. I don't know that it's worth it. (Informant 6, lines 176-179)

The process of becoming someone else was strongly conveyed by participants who reported a profound impact of side effects on identity. Side effects, explained Informant 2, change you - ultimately, they change who you are, what you look like, what you can do, and what you have to offer. Side effects "make you into a different person".

And they make you into a different person, um, but I know I'm going to live longer. You know what I mean I know the drugs are good, uh. That's why I take them. But I really wish that there wasn't that many side effects and they weren't so dominant in my life right now. (Informant 25, lines 284-287)

Side effects made participants feel different because they redefined what was normal for them. This was mentioned multiple times during the interviews when they said that side effects "become so normal" (Informant 20, line 289) or when they questioned if what the way they were feeling was "normal" (Informant 6, line 75). One participant even pointed out that she "didn't know what's normal anymore" (Informant 6 line 77). We found the next quote to be the best illustration of what happens to PLWH when side effects become their new normal and the best way to transition to the next process - living with.

Uh, [side effects], it's a chronic condition. I mean, you, you get used to it, it becomes your new normal. Um, like somebody asked me, I don't know who it was, some doctor asked me a few days ago "Do you get... are you tired or, yes, you... how much fatigue?" I'm like, "Well, I'm, I'm kind of always fatigued... but I've been living with that for a number of years, you know". So it is your new normal (...) So it's, it's a chronic thing, you know. (Informant 8, lines 930-940)

\section{Living with}

All of the participants talked about the experience of living with side effects and what that entailed. The constant presence of side effects meant that participants were forced to live in sync with antiretroviral drugs. In other words, they were forced to adjust their lives to match the progressive effects of the drugs throughout the day. Living with side effects also came with a great deal of uncertainty and limitations. These three sub-categories are explained next.

Living with side effects was akin to living with "very powerful" drugs in your system -drugs that have equally powerful effects on your body, your mind, and your life. Many participants explained how these drugs permeated their everyday lives. When we interviewed the following participant, he made a point of describing how his entire day unfolds under the influence of antiretroviral drugs and their side effects. Note that some sections of the quote were removed in the interest of space, but the sequence of the day was preserve to illustrate what it really means to live with drugs in your system every day:

The first thing I realize is that feeling of stunned a few hours after I take them. It's hard to describe. I guess it feels like being stoned in a way, but not... stoned in a... feeling sick and dizzy, mildly nauseous. And, uh, just being unable to concentrate (...) It lasts for 15 to half an hour. And then, once [the medication] hits me, it's like, "Oh!" Then, I know that it's hit me (...). And then, a few hours later, I notice that my vision is blurred (...). I mean, I can still read from a distance, but it's blurred and, I can tell that the pills are, at that time of the day, the pills are ticking in. Uh, throughout the rest of the day, it sort of focuses back into normal (...). So that takes me to about lunch time (...). I tend not to have an appetite ... So I have to force myself to eat. Um and I know it's because of the pills. So I'Il eat, I'Il force myself to eat without an appetite. Uh, the taste is pretty much, I can still taste [the medication], like it does affect my taste buds...just the flavour of stuff (...). And then, probably around 1:00, anywhere in the mid-afternoon, I'm just zomped (...). I need to take a nap. I really do, even if it's for an hour and then I'Il feel better, but it feels like 
I'm just, uh, worn out and I know it's from the pills. I mean, I'm living with this. So, what happens, I take a nap. It takes me too now into the evening time... dinner time, I will eat (...) I feel okay, I think, for the most part, the worst of it is over... for the day. Um, and now comes night time. I never had any problem sleeping until I started taking this Atripla. So I've had to get a doctor to give me medication to help me sleep (...). Okay, so that's to manage a side effect (...). Now, when I do finally get to sleep, I will have some of the strangest dreams, not necessarily nightmares. (Informant 16, lines 69-166)

Many participants offered similar descriptions of their day to day experiences while others emphasized that antiretroviral drugs took over (or dominated) their life the moment they developed side effects. There was a general consensus that you cannot live the life you want when you have side effects. As such, you have to adapt to a new way of life and learn to "live with it" - an expression used by many participants along with related terms such as "adjust", "adapt", "accept", "bear with", "get used to", "endure", and so forth. Learning to "live with it" was considered to be the only option, the only way to stay alive by continuing to take antiretroviral drugs and not letting side effects completely take over your life to the point of not wanting to live anymore. Learning to "live with it" was, in fact, the only way to regain some control over the powerful influence of antiretroviral drugs. This participant explains:

When you're on medication to save your life or to maintain your life... the horrible side effects I've learned to deal with it (...). You develop a plan and you have to not allow it to take over your life. Um, you have to take away the strength of the side effect to make it less, right. You have to develop a plan, battle it, a plan of attack or you're not going to survive, or you're going to want to throw yourself off the balcony, you know. Side effects can really wear you out. Living with side effects, you can either handle it and manage it or you can let it take over your life and your life won't be around for long after that. (Informant 15, lines 460-471)

Living with side effects also involved a great deal of uncertainty. Participants faced uncertainty in their day-today life because of the unpredictable and unstable nature of side effects (as previously described in category 1). Not knowing what will happen from one day to the next was a recurrent theme throughout the interviews. Living with side effects meant that participants had to live "day by day" which limited their ability to seek employment, engage in volunteer work, take part in social activities, and plan activities of daily living. Living "day by day" also meant that some days were good, some days were bad, and some days were simply too much to bear as suggested by the following quote.
So I'm living it, I'm living it day by day. Um, I have bouts of depression about it every... or, um, every now and then. (Informant 16, lines 256-258)

Not knowing what the future had to bring was another recurrent theme throughout the interviews. Participants faced uncertainty about the long-term effects of antiretroviral drugs, the continued presence of side effects over time, and the types of side effects they could potentially develop on their current or on a different treatment regimen. Not knowing what was coming next was like being on a "roller coaster" said one participant.

And, right now, I'm on this brand new thing (medication). So it's this, it's like a roller coaster. I'm not sure what's coming. And that makes me a little nervous. (Informant 15 lines 359-361)

Living with side effects was challenging because of the uncertainties involved in taking antiretroviral drugs that cause a range of side effects - some more subtle than others. Some side effects were clearly caused by antiretroviral drugs and were identified as such by participants. Others, on the other hand, were not so clearly linked antiretroviral drugs. Not knowing if they were experiencing "real" side effects as opposed to the effects of HIV, concomitant illnesses or other medications added to the burden of uncertainty reported by participants. By the same token, all of the participants discussed the issue of "not knowing" and mentioned something like this at some point during the interview: "I don't know if it's a side effect or HIV or what." [emphasis added] (Informant 26, line 93).

Participants were forced to live a "limited life" because of side effects. This term was used by Informant 27 to describe the extent to which side effects limited the possibilities of living a full (normal) life. Participants reported physical and mental limitations as well as limitations in activities and movement. Physical limitations included actual physical side effects such as the ones described in category 1 . But they also included the physical impairments cause by side effects which limited their ability to perform certain activities independently such as walking, doing house chores, lifting objects, climbing stairs, and so on. For example, one participant had to walk with a cane because of joint damage and residual pain caused by antiretroviral drugs. Mental limitations were widely reported by participants - to the extent that they actually outweighed physical limitations both in terms of severity and impact on daily life. Concentration, memory, and cognitive problems were the most common limitations mentioned by participants.

There are memory losses ... When you can't recall the date of birth of your child, that's pretty telling you 
know. And I can't go back and remember things ... Um, and there are times when I stay "stuck" and I wonder what I'm doing. And then, bam, it comes back to me you know. (Informant 27, lines 30-35)

All of the participants experienced some degree of impairment (whether physical, mental or both) and activity limitations. As a result, they were no longer able to do what they used to do or what they would normally do (e.g., work, go out, drink, eat, take care of themselves, take care of others, exercise, travel, date, etc.). Because their side effects were highly unpredictable and unstable, some participants had their movement limited both in terms of space and distance. They could no longer travel long distances, travel by car or public transportation, walk long distances, exit the house without knowing where the bathrooms are, leave the house for too long, stay at the same place for too long, to just give a few examples. This not only limited their movement and to some extent their freedom, but it also increased their chances of becoming socially isolated.

Well I don't go out that much unless there's a bathroom nearby. I don't go out that much...unless there's a bathroom nearby. Um, the heart palpitations, I, I walk a lot. Uh, but it's always close to home. It has a big impact on my life. Uh, I can't do what I used to do. (Informant 28, lines 53-64)

\section{Dealing with}

The process of "dealing with" emerged as a core component of the experience of side effects. Participants primarily focused on the various ways in which they tried to deal with side effects and the specific strategies they used. However, they also explained how side effects impacted their way of dealing with the treatment and why dealing with their HIV physician became so central to their experience. These three sub-categories will be discussed below.

Dealing with side effects, as one might expect, was discussed in great detail during the interviews. Ways of dealing with side effects included taking additional prescribed medications, smoking marijuana, changing diet and lifestyle, monitoring the self (e.g., weight, blood pressure, glucose), doing tests, doing your research on the internet, talking to others, and trying different strategies such as drinking water, changing the medication schedule, taking supplements, drinking Ensure ${ }^{\circledR}$, and using over the counter medications like Tums ${ }^{\circledR}$ or Imodium ${ }^{\circledR}$. Participants talked about the importance of dealing with side effects - of taking charge, making a plan, finding solutions, and ways of managing their situation. Yet, there was a general consensus that side effects were "never completely dealt with" (Informant 9, lines 742-743).

Um, to live with side effects, I find, you know, they say HIV is a chronic manageable disease. Yes, it is, but it's a lot of work and it's manageable providing that you take all the necessary meds to counteract the side effects. But if you don't, you know, then it's a whole other can of worms, right. (Informant 4, lines 190-193)

Taking additional prescribed medications was identified as the main way of dealing with (or managing) side effects. While the irony of taking more medications to deal with the side effects of antiretroviral drugs was pointed out by many participants, it was nonetheless considered to be the most effective way of achieving some results. Interestingly, a large number of participants in this study smoked marijuana to deal with their anxiety, headaches, insomnia, nausea, and loss of appetite. However, as one participant pointed out, access to medical marijuana remains a challenge because "doctors are hesitant to prescribe" (Informant 29, lines 916-917). This explains why participants had to resort to buying marijuana off the streets. Overall, dealing with side effects was not an easy process. Many participants described it as trial and error because they were never really certain about the best ways to manage their side effects and were left to figure this out on their own with very little support from providers:

They don't give us the proper information. Is it hard to say, "Okay, we're going to give you these three pills. Now, this one might cause this. This one might cause that. And this one might cause this. So you'll have to get vitamin D for this. You'll have to get this for that. You'll have to get something else for this." (Informant 29, lines 795-806)

Dealing with the treatment was something participants had to do as part of their experience with side effects. In short, this came down to the three options of staying on treatment, switching treatment, or stopping the treatment. Participants who stayed on treatment did so because they wanted to preserve their options for the future, they feared that side effects of other antiretroviral drugs could potentially be worse than their actual side effects, and they considered or were told by their treating physician that their current treatment was "working". Many participants mentioned the expression "if it's not broken, don't fix it" to explain why they stayed on treatment despite side effects. This participant explains:

I feel like my HIV is, is under control, these medications I've been on for, uh, close to eight years now, I guess, and, uh, they're working. So if it's not broke, don't fix it, right. (Informant 30, lines 123-125)

As previously stated in category 1, side effects was the most common reason for switching treatment. All of the participants had switched their treatment numerous times for this very reason. Switching was also seen as a way of 
dealing with a treatment that was failing - in this case, failing to preserve a certain quality of life and not necessarily failing to meet clinical outcomes. In fact, it was seen as the only way to deal with a treatment that was no longer "working" from the point of view of the person taking that treatment. While stopping the treatment was identified as a possible option by all of the participants, only a few of them had actually used it. One of them was Informant 31:

I was on the medication for a period of time. Uh, I did give it a break. I went off the medication for a year. They told me that I was going to get sicker if I was going to get sick. Well, my body never got sick. I was still ok my blood tests and stuff like that. Then they end up giving me this new medication. And now I'm back to the first medication (...). But I don't like to... I don't like the feeling of them. And I never liked them from day 1. (Informant 31, lines 9-17)

Dealing with the treatment was also described as trial and error process. However, unlike dealing with side effects, it was very much a shared process with their HIV physician. Participants exercised less control over how they dealt with their treatment which made it easier and more difficult at times.

During the analysis, it became very clear that HIV physicians were highly influential in shaping the experience of side effects. Because side effects are related to treatment, and treatment is related to medical practice, physicians played a key role in the recognition and management of side effects - or lack thereof. There was a shared understanding among participants that there are some great HIV physicians out there, but that most of them do not understand the experience of side effects nor do they pay attention to what patients are going through. One participant summarized this when she said:

Oh, I've talked to my doctor a lot. And it's like every time we have the same conversation. It's like, "I'm going off it, I don't want to take it, I don't want to take it." And it's like he... he doesn't listen to me. But I think that's... from my experience and like the experience of my friends and everything. I think there are doctors who are amazing. But I understand also that it doesn't... they don't want people to die when there's an option, when there's a drug available that will prevent that. And I don't think that they always understand that sometimes, you know, the side effects are worse than the benefits. (Informant 6, lines 36-47)

Dealing with HIV physicians was challenging for the majority of participants. Not only did they struggle to have their side effects recognized and managed, but they also found it difficult to get their views heard without coming up against the hegemonic discourse on treatment and its benefits (including its life-saving benefits as illustrated by the quote below). Through their interactions with HIV physicians, they came to realize that side effects are simply not a priority staying on treatment and achieving clinical outcomes are. As a result, they felt that side effects were normalized, minimized, dismissed, ignored and even ignored by their physicians.

And I told my doctor about it and he's like, "Well, this is common with these and you have to, you know, just keep taking the pills no matter what because, uh, it's your life you're life you're dealing with right here. (Informant 5, lines 41-43)

Many participants were made to feel that side effects were about them (e.g., their diet, lifestyle, age, body, and attitude), not about the antiretroviral drugs. They were also left to figure things out on their own, including doing the research on side effects, finding ways of dealing with them, requesting tests and additional medications, asking for a treatment switch, and demanding answers about the nature of their side effects. In response to his experience of dealing with his HIV physician, one participant said the following:

Like, where are these doctors (from the 80s and 90s)? They don't exist anymore. You walk in, "What's wrong?" "Well, I'm feeling this thing here..." And it's like, "Oh, right there? Yes, okay, try this." I didn't come here for a pill. I came here to find out why this is so soar. Like to this day I still have... I'm so soar in the kidney area and he still hasn't... not been dealing with it. (Informant 29, lines 863-871)

To sum up, it was obvious that participants could not deal with side effects with some success without dealing with their HIV physician first and the treatment second. This further complicated the experience of side effects and made it a more challenging experience overall.

\section{Category 3: The Connections}

The last category specifically addressed the second and third objectives of the study. It emerged from the same data as other categories, the only difference being that the analysis was more clearly focused on "connections". Three types of connections were identified and will be discussed next: connections with people, things and systems.

\section{People}

During the analysis, we found that side effects created new connections between participants and three distinct groups of people: medical specialists, specialized health care providers and peers. Because side effects impacted multiple body systems, it was not uncommon for participants to be refereed to medical specialists. The specialists most commonly mentioned during the interviews were endocrinologists, 
cardiologists, nephrologists, ophthalmologists, psychiatrists, and neurologists. Participants were refereed to specialists to get an additional medical opinion on new and not yet diagnosed side effects such as blurred vision:

I've noticed my eyes have been more, uh, blurry since I've taken this new medication. I've been on it now for three months. I can hardly see. Like everything seems blurrier, something... but then again, my one eye, I can't see out of this eye, because I had an accident (...). I'm not sure if it's from the medication or if it's from something else. So I got an appointment with the eye doctor so they'll be able to tell me everything. (Informant 21, lines 24-30, 74-76)

Participants were also refereed to specialists in order to manage their drug-induced diabetes, hypertension, myocardial infarction, hypercholesterolemia, peripheral neuropathy, and so forth. These side effects were more challenging to manage which resulted in long-term and even sometimes lifelong follow-up by medical specialists. It was not the case for the following participant who eventually recovered from her peripheral neuropathy, but it was the case for participants who developed cardiovascular and metabolic side effects.

That was early 2000. I was taking Kaletra and, uh, um, I think 3TC, yes, I got severe neuropathy to the point where I saw a neurologist and like it was pins and needles and, um, I had lost sensation of the extremities, the hands and feet, like it felt like you're... when you sit on your foot and it falls asleep there, you know, you go to walk and it would... I would sometimes wake up in the morning and step out of bed and just flop to the floor because my feet, I couldn't feel the ground below me. And doing dishes, sometimes, I couldn't feel the, the dishes or I'd hold a cup and then drop it (...). And it was extremely painful. (Informant 10, lines 66-75)

Adding new and sometimes permanent connections with medical specialists added to the level to complexity of dealing with side effects (as described in category 2). This was clearly pointed out by all of the participants who felt that adding more people and subsequently more medications did not solve the problem - it only added to it.

All of the participants had been in contact with specialized health care providers at some point during their experience with side effects including nutritionists, physiotherapists, and pharmacists. Connections were formed with these providers as a way to deal with and alleviate their side effects. Participants with cardiovascular and metabolic side effects reported the most connections because they typically worked with an entire team of providers to change their diet, exercise, control their blood pressure and/or glucose level, and reduce their health risks.
Yes, right now, I'm trying to change my diet. It's easier said than done, right, because you're so used to eating a certain way, right. So... and I will learn more in the next couple of weeks, because, um, I am starting cardio rehab. So, um, seeing a dietician, uh... you know, there's a whole team that will work with you. (Informant 4, lines 130-133)

Participants were referred to nutritionists to deal with side effects such as diabetes and hypercholesterolemia as well to alleviate gastro-intestinal side effects such as diarrhea, anorexia, and bloating. They were also referred to physiotherapists to assist with pain and reduced mobility. Access to physiotherapy was an issue raised by participants who were told by their HIV physician that they needed it but did not have coverage for it.

The old medications almost destroyed my knees. I couldn't go up or down the stairs. When I discovered it was the medications that caused that, I stopped them. It took a year to go away. And now that I take ... I'm not sure, but I still have pain in my knees (...). The doctor told me to go see a physiotherapist. It is extremely expensive ... But I don't have insurance to cover that so I'm trying to figure out how ... (Informant 24, lines 10-15, 261-271)

While pharmacists possessed the most knowledge about antiretroviral drugs, they did not play a major role in the management of side effects. When pharmacists were available and accessible, participants connected with them to obtain information about antiretroviral drugs and side effects. However, as pointed out by the next participant, this was not always the case.

I like when the pharmacist comes in and... Because he's sort of more... you know, that's his thing, that's what they do. Right? So, I like when the pharmacist ask me questions, but it doesn't always happen with every visit. (Informant 8, lines 525-531)

Participants agreed that connections with specialized health care providers could be helpful to a certain extent, but only if the services they provided were accessible and consistently offered. This was clearly not the case considering that some participants had never even met with a pharmacist to discuss their side effects and learn more about their treatment.

Participants unanimously identified community-based organizations and peers as their primary source of information on side effects. While the Internet was a useful portal of information for all participants, it did not measure up to the expertise of peers and their firsthand experience with antiretroviral drugs. This was more valuable to participants than what health care providers had to offer because it was based on lived experience - the experience of taking the same antiretroviral drugs, having the same side effects, dealing 
with these side effects of a daily basis, and facing similar challenges. Peers were the principal "point of contact" for information and advice on side effects as suggested by the next quote:

I never spoke with a pharmacist. I spoke with a friend of mine who is also HIV positive. Him and I started medication at the same time. So he was sort of my main contact. (Informant 3, lines 152-153)

I often talk to one of my good friend. He really took all the different medications and well ... He is really knowledgeable about the medications. So I'Il talk to him and say "Ok, so this is happening to me. Could it be related?" (Informan1, lines 488-491)

Peers were, by far, the most credible source of information and possessed an expertise that could only be obtained by knowing what side effects actually feel like and knowing how to explain it to others who are feeling the same way. During his interview, one participant said:

Once in a while, you ask a question ... And then, another person with HIV will give you a clearer answer than the doctor ... Or his own words you know, you can feel it as oppose to the doctor, it's cold. The doctor will tell you ta, ta, ta, and then turn the page and start typing on a computer. Wow! The human contact just went out the window. (Informant 19, lines 731-740)

Peers played an important role because they not only understood what others who experience the same side effects are going through, but also what they need to know in order to deal with their situation and ways of sharing information in an accessible and meaningful way. Participants had learned a great deal from peers over the course of their experience with antiretroviral drugs, especially when they started their first treatment regimen. During the interview, many participants recalled hearing about some side effects for the first time in peer groups and getting validation from others when they were unsure about their own side effects. This was repeatedly mentioned by participants who experienced side effects that are rarely discussed in clinical settings such as body shape changes (also known as lipodystrophy). As such, they insisted on the importance of ensuring access to peer support groups and encouraging peer-to-peer knowledge exchange as a way to support to people who experience to side effects.

\section{Things}

In addition to creating new connections with people, side effects created new ways of connecting with three categories of "things": drugs, devices, and objects. Here, we use the term 'drugs' to designate prescription medications, over-thecounter medications, and illicit drugs (i.e., marijuana). Side effects increased the presence of medications in the lives of participants - making side effects more challenging to manage than HIV itself. This was pointed out by many participants who took a large number of prescribed medications (including insulin) and over-the-counter medications, up to 10, 20, 30, 40 and even 50 a day for some.

I take 55 medications each day, of which 10 are for HIV only. All the other ones, are for the side effects and I know that I'm stuck living with this for the rest of my life. These are things that will never go away. You just have to get used to taking a handful of medication in the morning, and another one at dinner time, and a few ones in the evening. It becomes part of a routine. But it's not just the medications, it's the glucometer to check your sugar, and the injections you have to give yourself. So you're always carrying a backpack full of stuff. (Informant 32, lines 243-250)

There was a general consensus that side effects create a never-ending vicious cycle in which medications are used to manage a problem initially caused by medications. Participants described how new medications were added one by one to deal with each side effect individually to the point of making them feel like "pill poppers constantly popping pills" (Informant 29, line 762). The capacity of side effects to create and multiply connections with prescribed and overthe-counter medications was simply put by the following participant who said:

The medical profession got better at dealing with side effects, you know, for insomnia, they prescribe you sleeping pill or, for heartburn, ranitidine... That kind of stuff. Uh, if you develop some form of anxiety or depression, they put you on medications for that (...). You add the number of pills for HIV and add all those other pills they give you to manage your side effects. (Informant 33, lines 300-314)

As previously mentioned, many participants discussed their use of marijuana to deal with side effects. Some participants were already familiar with the drug and used it before developing side effects. However, many participants only started to smoke marijuana because of their side effects and not because they wanted to "do drugs". As one participant recalled:

I was told "smoke a joint, you're going to get your appetite" (laugh). I don't even do drugs. Where am I going to go find a joint to smoke? (Informant 13, lines 124-126)

The idea of creating a new connection with marijuana made some participants nervous because of the potentially addictive nature of that connection. By the same token, participants did not feel particularly comfortable with the idea of forming permanent lifelong connections with medications which were seen as equally addictive in their own way. 
It was clear that participants were strongly connected to 'drugs' because they played such an integral part in the response to side effects. Other types of connections, however, were less clear during the interviews. The analysis allowed us to "dig deeper" and expose two additional types of connections: connections with devices and objects. We found that participants were connected to a range of devices because of their side effects including glucometers, blood pressure monitors, inhalers, and so forth. In turn, these devices were connected to prescription medications. We found evidence of this phenomenon in numerous interviews including the interview we conducted with Informant 32 who made reference to his glucometer and insulin in the above quote. One interview stood out as a clear example of such a phenomenon. We pulled a lengthy quote from this interview to illustrate the multitude of connections that form in the context of side effects.

I only take three, uh, HIV meds but then I also take antivirals to, you know, make sure that I don't get opportunistic infections such as herpes outbreaks. Uh, that's one pill. I take an antidepressant pill (...). Um, so there's also, I mean, I have in the past broken out into skin rashes and I've had to take Reactin. So because of it I take Reactin. I don't take a full, uh, Reactin every day because, as I said, I'm on a lot of pills. I take a half a pill of Reactin to make sure that none of that happens. Uh, you know, I'm on three different inhalers. Uh, I've got anti-cholesterol pills that I'm taking. I'm taking, a baby Aspirin. Uh, I'm also taking, Metoprolol, which is, uh, you know, for blood pressure ... And then I'm also taking a beta-blocker and an ace inhibitor. And then for the diabetes, I take Diamicron, uh, to keep the blood sugar from getting too high. And then I take Metformin for making sure that it doesn't get too low. And it's still a balancing act, right (...). I've learned now that I have to carry a bag, uh, because you never know what may happen. And if you end up not going home, at least, you have the backup plan and you've got some in your, in your bag, right. But sometimes, you know, I run around with a bag with all these different things (Laughs) and it's like, it's crazy, right. I mean, you know, I've got my testing kit, I've got my inhalers in there, you know. (Informant 4, lines 27-46, 141-152)

Like drugs, devices were very present in the lives of participants. They learned how to operate these devices, what to do with the information generated (e.g., blood glucose), and how to adjust their medications based on that information. They carried these devices with them throughout the day and made sure they always had a "backup plan" just in case. It became obvious that devices came with an additional set of responsibilities. Devices were far from being neutral things. In fact, they exercise a great deal of influence over participants and how they organized their routine, activities, travels, and life in general.

During the analysis, we also found that side effects profoundly changed the way participants related to familiar objects in their environment as well as their relationship to food and fluids. Participants talked in great lengths about their connection with one particular object: the toilet. While this object may seem trivial to most people, it was not for participants who lived with chronic diarrhea who represented a large portion of our sample. In fact, their whole life was organized around this object. They restricted their movement and planned their activities to maintain proximity to a toilet. The following clearly illustrates this:

But it got to the point that I did not want to leave my apartment. I became very much a hermit. Or at least, I didn't leave the vicinity of a five minute walk from my toilet or a toilet that I knew about. And to this day, I know where all the publicly accessed toilets are probably within a seven to ten block radius of this apartment. So if I go for a walk, I know where I can go in a moment's notice. (Informant 9, lines 143-149)

All of the participants who had chronic diarrhea knew where the toilets were at all times. This information determined their itinerary, how far they could go, where they could, who they could go with, and what they wore. Maintaining a constant connection to a toilet became a priority for them - something they needed to plan for and always think about. At times, this also meant they could not leave the house or take part in activities that kept them far away from a toilet. Despite all the planning, chronic diarrhea remained challenging to manage.

I have to watch what I eat, though. I can still get the diarrhea just as a snap. That happened yesterday at Father's Day at my son's house where I had supper. I was sitting down and all of a sudden it happened, uh, no warning. So we had to leave, you know. If I go out for any length of time, I wear a Kotex pad so... if it happens, it doesn't ruin my clothes, you know. (Informant, 11, lines 205-211)

Controlling what food to eat and how much (and which) fluids to drink was common to all participants, but especially those who experienced gastro-intestinal, cardiovascular, and metabolic side effects. Participants described the different ways in which side effects changed their relationship to food. All of them were forced to change what they ate, how much they ate, and when they ate. Food became yet another thing be managed, leaving very little room for the enjoyment of food. In fact, many participants talked about their connection to food in a purely mechanical way: it was planned, timed, measured, controlled, replaced by Ensure ${ }^{\circledR}$, and forced into the body. Side effects also changed their relationship to fluids. Many participants had to reduce their water intake 
while others had to reduce or avoid certain fluids like coffee, alcohol, and soft drinks. All and all, side effects completely transformed the way participants connected to objects and the purpose they served by turning them into side effects management "tools".

\section{Systems}

The analysis revealed that participants were connected to three distinct systems which were influential in shaping their experience with side effects: the knowledge systems, the health care system, and the state welfare system. Building on the findings presented thus far, we identified two competing knowledge systems: 1) the dominant system in charge of producing scientific and medical knowledge on side effects, and 2) the alternative system of knowledge created by lived experience experts. Participants were very critical of the dominant system in which the vast majority of knowledge on side effects is produced by pharmaceutical companies. And yet, they had to rely on it for most of their information on side effects. One participant reflected on the fact that the expedited process set up at the beginning of the HIV epidemic to approve antiretroviral drugs contributed to a system of "trial and error" where drugs were widely tested on PLWH and were used without fully knowing their side effects. Many participants felt like "guinea pigs" because of side effects they experienced as a result of this system - including many side effects that were unknown to their physicians. Throughout the interviews, there was a general call for pharmaceutical companies to increase their understanding of side effects and reduce the burden of side effects faced by PLWH.

Well, unless the people that are developing these drugs, I think they should be the ones taking them. I really do. Don't make us the guinea pigs. You invented this drug. You put it together. So take it and see what it feels like, you, when you're not positive. You know. Our life is bad enough as it is. (Informant 11, lines 238-241)

Knowledge produced by pharmaceutical companies was considered to be incomplete because it was largely based on male clinical trial participants and it failed to provide a full picture of the actual side effects of antiretroviral drugs. A large number of participants had been in a situation at some point during their treatment where they experienced a side effect that was not listed in the product monograph published by the pharmaceutical company. Informant 24 was one of them. He experienced severe joint pain but he "could not find it on the list of side effects" (lines 123-124). Informant 12 was also part of that group. His mouth became extremely pasty and dry but since this side effect was not listed by pharmaceutical companies, it went unrecognized and untreated by his physician. The importance of having an alternative system of knowledge production by and for PLWH was clearly stated by participants. As previously described in this category, this system was an important source of information, validation and advice for participants. Being connected to such a system made a real difference for participants.

Side effects intensified and multiplied the connections between participants and the health care system. Participants were more frequently in contact with this system as a result of their side effects being unresolved and/or being complicated to manage. They saw more health care providers, took more medications, had more tests to undergo, and more appointments to attend - all of which contributed to the burden of side effects. Participants explained that the health care system is predominantly geared toward treatment adherence and the achievement of positive clinical outcomes. It does not serve the interests of people who struggle with side effects. Key issues identified by participants included the lack of information and conversation about side effects, the "5 minute" consultation model which limits interactions with physicians, the overemphasis on viral load and CD4 count, the overreliance on medications to treat all problems, the "pathologization" of normal reactions to side effects, the authoritarian and paternalistic attitudes of physicians, the tendency minimize and even disregard the experience of side effects, and the lack of understanding of what that experience entails for PLWH. Within this system, participants were not taken seriously, especially when they reported side effects. A few participants provided examples of the types of advice given by health care providers to illustrate this particular point. We selected three quotes to show why participants felt so strongly about this issue:

For the night sweats, I talked to a nurse who works with my doctor and she told me "It's probably because the room is too hot or the blankets are too warm". I said "You don't say!" Sometimes, it seems difficult for us to be understood. I understand that providers want to de-dramatize things but come on. (Informant 24, lines 64-73)

Last time, my doctor told me I was in distress. And I'm not a stressed person in life, but when I'm at the doctor's office, I feel in distress because I want solutions. I want answers and I'm not getting any and that creates a distress. My doctor was telling me "You should relax, go to yoga, consult someone ..." Yoga won't solve my problem with lipodystrophy and my pasty mouth. I always found that my side effects were not taken seriously." (Informant 12, lines 300-311)

I've had one doctor suggest to me, uh, years ago, he goes, "Well, can you tell that that is the side effect when you're experiencing it. So you can kind of look 
at it as an objective observer and say, "This isn't me, this is the side effect"... and then, then it'll be okay". I couldn't do that. The side effects just completely took me over. (Informant 20, lines 492-498)

In their interactions with the health care system, participants who became more assertive and demanded answers, solutions, or even a change in physician were labelled and treated as "difficult, problematic or aggressive patients". This was clearly explained by one participant whose physician failed to mention that his current treatment regimen could cause diabetes. After he raised this point with his physician and expressed his discontent with the fact that this information was not shared with him, he was subsequently told to go see a psychiatrist because he had a "temper" (Informant 29, line 819). Being closely connected with the health care systems did not necessarily help participants with their side effects. In fact, it often created more problems or more frustrations as suggested above.

All of the participants had strong ties to the state welfare system as a direct result of their side effects. The majority of participants could no longer hold a full-time job which left them in a precarious financial situation with low income or no income at all. For this reason, they had to rely on state programs for financial assistance with living expenses and coverage of prescription drugs, dental services and vision care. Many participants also relied on subsidized housing programs or housing facilities for PLWH in addition to community-based programs that provided access to nutritious food and supplements. While they were grateful for the support and assistance, participants also felt "stuck" within this welfare system. This participant explains:

The cost is one of the biggest side effects basically from going back to work. They keep us poor. Like my, my worker told me, "Yes, yes, we'll cover your meds." I said, "For how long?" She said, "Well, 'till your benefits at your work." I said, "Yes, but that's only $\$ 10,000$ a year. My meds are \$3,000 a month." I said, "How am I supposed to do that for three months and then what after?" "You guys won't help me anymore because I' $m$ working and I have benefits and then I got to decide between rent and food. So you're... you're keeping me here." The government by not forcing the pills to be cheaper, like all the people who are HIV-positive should be able to have it cost effective. (Informant 29, lines 273-284)

With the support of disability assistance programs, some participants managed to "get out of the system" and hold a part-time job while also maintaining full coverage of their prescription drugs. For many participants, however, the fluctuating nature of their side effects did not allow them to consider that option. They had no choice but to remain "in the system".

I'm not able to work anymore. Uh, I do some volunteer work. But I can't say that I'm going to be there at a certain time at a certain day because I'm not, I'm never sure, uh, you know, uh, everything's always tentative, like, you know, as long as I feel all right, I'Il be able to go. But I can't say that I'm going to absolutely be there on time. (Informant 18, lines 70-74)

All of the participants were in precarious financial situation despite being strongly connected to the state welfare system. The idea of aging within this system was extremely stressful because of the way government and private pension plans are set up. One participant summarized his situation as follows:

"Because disability stops at 65. My drug coverage stops at 65 . Well, what does that mean? It means I have no pension. It means that I'm going to be on government drugs plans. And they don't always have on their formulary the HIV meds that I want." (Informant 9, lines 600-606)

\section{Discussion}

This study is, to our knowledge, the first one to explore and describe the experience of side effects from the perspective of PLWH. Our findings suggest that side effects are more complicated than they seem. The first step in broadening our understanding of side effects is to pay closer attention to the context in which they occur and how they manifest. The vast majority of PLWH will experience a combination of immediate, progressive, minor, severe, transient, permanent, hidden, and visible side effects. As such, it is important to ask PLWH about the types of side effects they experience and what happens when they all come together - what does that look like for them and how does it affect their lives?

The second step in broadening our understanding and subsequently improving our response to side effects is to recognize that every person is unique. Every person has their own story to tell and their experience is far more complex than a checklist of symptoms. This experience will forever change who they are and how they see themselves, it will challenge their own assumptions about health and illness, and it will redefine what normal feels like. This experience is something they will have to live with every day for the rest of their lives. It will impact their body and their mind. As a result, it will set limits on what they can do, where they can go, who they can be, and how they can engage with others. They will live in a constant state of fluctuation and uncertainty due to the nature of side effects. Dealing with this experience will not be easy. It will involve a lot of research, experimentation, negotiation, planning, discussion, frustration, and unanswered questions. 
At the end, it will all come down to medications: taking more medications to solve a problem created by medications in the first place. This experience will raise questions about what we know and how we know. It will expose issues with the way pharmaceutical companies produce knowledge on side effects and how this impacts clinical practice. It will also create opportunities for new ways of knowing to emerge based on lived experience. Through this experience, they will develop strong ties to the health care and welfare systems. At times, this will make them feel supported. Other times, it will make them feel trapped.

The third and final step is not about understanding or improving our response to side effects. It is about demanding change: a change in discourse and a change in culture. The study findings clearly suggest that a change is needed to ensure that side effects are part of the discourse on HIV treatment, instead of being erased from it. In recent years, this discourse has become increasingly focused on the idea that HIV treatment is now simpler, more manageable, better tolerated, less toxic, and more effective. As suggested by the study findings, participants were feeling the effect on this discourse every time they interacted with health care providers. It reduced their chances of being heard, being taken seriously, and being cared for. Unless we change the discourse on HIV treatment, it is unlikely that these issues will be addressed anytime soon. A change in culture was also identified as a priority in this study. The culture of silence that prevails in clinical settings further exacerbated the problems faced by participants. Because of this culture, side effects were not discussed, assessed and properly managed, treatment benefits were amplified to the point of invalidating all concerns related to side effects, and people who experience side effects were repeatedly silenced by health care providers. This culture has not been challenged to date in the field of HIV.

\section{Conclusion}

In conclusion, we want to insist on the fact that side effects are a real concern as they continue to affect PLWH in so many ways. The findings of this study are particularly important at this point in time in the field of HIV because antiretroviral drugs are now considered to be the cornerstone of the response to the HIV epidemic. It is our hope that side effects will find their way back into the conversation as more and more people are being put on treatment (including HIV-negative people) and encouraged to start treatment at the time of diagnosis. It is our contention that there can be no conversation on treatment expansion without a real conversation on the intended and unintended effects of this treatment.

\section{References}

1.Esté JA, Cihlar T. Current status and challenges of antiretroviral research and therapy. Antiviral Research 2010; 85(1): 25-33.

2.Hawkins T. Understanding and managing the adverse effects of antiretroviral therapy. Antiviral Research 2010; 85(1): 201-09.

3. Margolis AM, Heverling H, Pham PA, Stolbach A. A Review of the toxicity of HIV Medications. Journal of Medical Toxicology 2014; 10:26-39.

4.Reust CE. Common Adverse Effects of Antiretroviral Therapy for HIV Disease. American Family Physician 2011; 83(1): 1443-51.

5.Prosperi MCF, Fabbiani M, Fanti I, Zaccarelli M, Colafigli M, Mondi A, D'Avino A, ... Di Giambenedetto S. Predictors of firs-line antiretroviral therapy discontinuation due to drug-related adverse events in HIV-infected patients: a retrospective cohort study. BMC Infectious Disease 2012; 12: 296 .

6.Monterssori V, Press N, Harris M, Akagi L, Montaner JSG. Adverse effects of antiretroviral therapy for HIV infection. CMAJ 2014; 170(2): 229-37.

7.Al-Dakkak I, Patel S, McCann, E, Gadkari A, Prajapati G, Maiese EM. The impact of specific HIV treatment-related adverse events on adherence to antiretroviral therapy: A systematic review and meta-analysis. AIDS Care 2013; 25(4): 400-14.

8. Braithwaite RS, Goulet J, Kudel I, Tsevat J. Justice AC. Quantifying the Decrement in Utility from Perceived Side Effects of Combination Antiretroviral Therapies in Patients with HIV. Value in Health 2008; 11(5): 975-9.

9.Park-Wyllie LY, Strike CS, Antoniou T, Bayoumi AM. Adverse quality of life consequences of antiretroviral medications. AIDS Care 2007; 19(2): 252-7.

10. Wilson HS, Hutchinson SA, Holzemer WL. Reconciling Incompatibilities: A Grounded Theory of HIV Medication Adherence and Symptom Management. Qualitative Health Research 2002; 12(10): 1309-22.

11. Vervoort SCJM, Borleffs JCC, Hoepelman AIM, Grypdonck MHF. Adherence to antiretroviral therapy: a review of qualitative research. AIDS 2007; 21(3): 271-81. 
12. Wong WKT, Ussher JN. Life with HIV and AIDS in the Era of Effective Treatments: "It's Not Just about Living Longer!". Social Theory \& Health 2008; 6, 117-31.

13.Gagnon M, Holmes, D. Bodies in mutation: Understanding lipodystrophy among women living with HIV/AIDS. Research and Theory for Nursing Practice 2011; 25(1): 23-38.

14.Gagnon M, Holmes D. Women living with HIV/AIDS and the bodily transformation process known as lipodystrophy: A grounded theory study. Journal of Research in Nursing 2012; 17(3): 215-28.

15.Persson A. Incorporating Pharmakon : HIV, Medicine, and Body Shape Change. Body \& Society 2004; 10(4): 45-67.

16.Persson A. Facing HIV: Body Shape Change and the (in) Visibility of Illness. Medical Anthropology 2005; 24: 237-64.

17.Mykhalovskiy E, McCoy L, Bresalier M. Compliance/ Adherence, HIV/AIDS and the critique of medical power. Social Theory and Health 2004; 2(4): 315-40.

18.Persson A, Race K, Wakeford E. HIV health in context: negotiating medical technology and lived experience. Health 2003; 7(4): 397-415.

19.Persson A. Non-infectious coporealities: tensions in the biomedical era of 'HIV normalisation'. Sociology of Health \& Illness 2013; 35(7): 1065-79.

20.Rosengarten M, Imrie J, Flowers P, Davis MD, Hart GJ. After the euphoria: HIV medical technologies from the perspective of their prescribers. Sociology of Health \& Illness 2004; 26(5): 575-96.

21.Charmaz K. Constructing Grounded Theory: A Practical Guide through Qualitative Analysis. London: Sage, 2006.

22.Charmaz K. Constructing Grounded Theory (2nd ed.). London: Sage, 2014.

23. Public Health Agency of Canada. HIV/AIDS Epi Updates, 2010. Retrieved from: http://www.phac-aspc.gc.ca/aids-sida/ publication/epi/2010/pdf/EN_Intro_Web.pdf

24. Birks M, Mills J. Grounded Theory: A Practical Guide. Thousand Oaks: Sage, 2011.

25. Paillé P. L'analyse par théorisation ancrée. Cahiers de recherche en sociologie 1994; 23: 147-81.

26.Gagnon M. Understanding the experience of reconstructive treatments from the perspectives of people who suffer from facial lipoatrophy: A qualitative study. International Journal of Nursing Studies 2012; 49(5): 539-48.
27.Gagnon M. Re-thinking HIV-related stigma in health care settings: A qualitative study, Journal of the Association of Nurses in AIDS Care 2015; 26(6): 704-19. 